\title{
A Cross-Disciplines and Cross-Sector Mixed-Methods Examination of Design Thinking Practices and Outcome
}

\author{
Danielle Lake $^{1}$ (D) $\cdot$ Kathleen Flannery ${ }^{2} \cdot$ Morgan Kearns $^{3}$
}

Accepted: 23 December 2020 / Published online: 18 February 2021

(C) The Author(s) 2021

\begin{abstract}
This mixed method study investigated design thinking (DT) practices and outcomes from across disciplinary frameworks within one institution of higher education. Building upon prior DT studies, it examined three interlocking research questions: What DT practices are being implemented across the curriculum? What kinds of outcomes do faculty observe? What are the significant relationships between particular practices and observed outcomes? Thirty-five courses were examined via a faculty survey adapted from Liedtka and Bahr (2019), and a semi-structured interview created by Lake, Ricco, and Whipps (2018). In alignment with liberal arts educational practices, the most frequently utilized DT practices included working in teams that recognize diverse contributions and engaging in active listening in order to find shared meaning. Consistent with expectations for project- and team-based courses, faculty felt such practices yielded valued outcomes, concluding DT practices built trust across teams and increased the quality of solutions. Relationships between practices and outcomes revealed the utilization of more ethnographic tools was associated with a lower frequency of expanding relationships and resources, and that a greater focus on design criteria to find an ideal solution hampered
\end{abstract}

\footnotetext{
Danielle Lake is the Director of Design Thinking and Associate Professor at Elon University. Her scholarship explores the connections and tensions between design thinking, wicked problems, and the movement towards public engagement within higher education. Her current projects focus on exploring the long-term impact of design thinking practices, place- and project-based learning, and pedagogies of resilience. Lake is coeditor of the book series, Higher Education and Civic Democratic Engagement: Exploring Impact, with Peter Lang Publishing. Recent publications can be found at http://works.bepress.com/danielle_lake/
}

Kathleen Flannery is a Professor in the Psychology Department at Saint Anselm College. Her research program examines cognitive processes such as memory and attention using novel tasks created for online testing. Flannery's team has designed an intervention to improve working memory in college students, which they are evaluating. She leads the Design Thinking for Social Innovation Initiative at the College.

Morgan Kearns is an undergraduate student at Elon University studying economics with a focus on economic equity. As a member of the Isabella Cannon Leadership Fellows program, she has been able to pursue her interest in increasing other's capacity for change. Her current project supports making leadership development opportunities more accessible for students across campus.

Danielle Lake

dlake@elon.edu

Extended author information available on the last page of the article 
efforts towards trust building. These findings suggest DT requires time and trust which can be constrained by the imposed deadlines of semester-based projects. The survey and interviews pointed to both similarities and differences between disciplines in DT practices. Future research investigating design thinking pedagogy should include faculty, students, and stakeholders with multiple touchpoints for assessment to identify learning experiences that build change-making capacities and yield genuinely valuable and viable real world projects.

Keywords Design thinking · Team and Project-based learning · High impact practices · Interdisciplinarity $\cdot$ Mixed model design $\cdot$ Experiential learning

Thus far research on design thinking (DT) has mostly emerged from limited qualitative case studies (Calgrenet al., 2016; Lake et al., 2019) and traditional return on investment numbers (Forrester Research Inc., 2018; Sheppard et al., 2018). While prior research on DT practices and outcomes from the business, non-profit, and government sector has shown that moderate engagement with core DT practices increased valued outcomes and practitioner flexibility (Liedtka \& Bahr, 2019), researchers have not yet examined if similar practices and outcomes can be seen within higher education pedagogies. Efforts to critically interrogate the role of narrowly constructed frameworks and practices in academia are still needed. Responding to current research findings (Brodie, 2014; Vink, 2019), this study explores what DT practices might be most effective for generating change and building capacities. It also highlights various approaches and perceived outcomes across disciplinary frameworks, exploring the potential merits and drawbacks of DT practices.

This paper summarizes the design and findings from a mixed methods study that investigated DT practices and outcomes from across disciplinary frameworks and compares findings from higher education to those emerging in other sectors. Building upon prior DT studies (Lake et al., 2019; Liedtka, 2017; Liedtka \& Bahr, 2019) and studies examining high impact practices within higher education (Lake et al., 2018), it was designed to address three interlocking research questions:

- What DT practices are being implemented across the curriculum?

- What kinds of outcomes do faculty observe?

- What, if any, are the significant relationships between particular practices and observed outcomes?

This research included the adaptation of a previously validated survey by Liedtka and Bahr (2019) assessing DT practices and outcomes, and semi-structured interviews. This study assessed practices and outcomes across 35 courses and programs integrating DT practices and compared findings to prior research (Liedtka \& Bahr, 2019).

\section{Context}

The context for this research is particularly relevant. The authors are DT practitioners and researchers - a director, faculty member, and student - who both value and critique DT as a method for resiliently addressing wicked problems. The study emerged 
from conversations by the researchers to not only better understand the value and the limitations of DT across higher education curriculum, but to also enhance those practices. It also emerged from a desire to compare the perceived value and challenges of teaching DT within higher education to research emerging from other sectors. We hope results will inform and reform DT pedagogies that build changemaker capacities.

This study is situated at Elon University, a mid-sized, private, liberal-arts institution located in the Southern United States. DT was a natural fit given the University's strong and long-standing commitment to engaged, experiential learning and innovation. The timing for this study occurs four years after beginning a grant funded university-wide DT initiative that included infusing DT across university courses and programs. ${ }^{1}$

\section{A Review of the Literature}

"The only way to achieve the transformational potential of DT is by understanding the experiences that design done well triggers in the human beings who use it" (Liedtka et al., 2021).

\section{What Is Design Thinking?! Stepping into the Fray and Staking a Claim}

As an iterative, project-based, and collaborative problem-finding and solving process (Brown, 2009; Seidel \& Fixson, 2013), we argue DT pedagogies - at their best - require students become more aware of their situatedness; prompt self- and other-awareness (Lake et al., 2019), encourage empathetic listening, critical observation, and creative collaboration (Benson \& Dresdow, 2015; Royalty et al., 2014) that yields valued, viable responses to wicked problems and builds the capacities of all stakeholders (Costanza-Chock, 2020; Wagoner, 2017). A plethora of visual DT models, tools, and methods exist across sectors (including education, government, business, and non-profit platforms). For us, DT 1) begins by framing not only the situation, but also one's own situatedness within the complexities; it includes 2) an iterative exploration across space and time that values diverse knowledges; it requires 3 ) the generation of divergent possibilities, and 4) the prototyping of these possibilities (actionable opportunities to enact and test ideas in relationship with others). As an iterative, experimental, relational, and context-responsive process, it 5) leverages these commitments into the cultivation of valued change. This framework for DT pedagogies visualizes the connections to popular education efforts emerging from the work of Paulo Freire, Grace Lee Boggs's place-based philosophic-activism, and Creative Reaction Lab's Equity-Centered

\footnotetext{
${ }^{1}$ This study assesses the curricular innovations that emerged from a university-wide initiative that began in 2016. One of the first programs that emerged from this initiative introduced first-year students to DT by integrating workshops into required first-year seminars. At the same time an immersive semester experience for third and fourth-year students was piloted. This immersion created a studio experience where four integrated courses were completed as a single, community-based learning experience. In addition, non-credit bearing "pop-up courses" were designed to support a wider variety of student needs. Following on the heels of these initiatives, the Center launched a faculty development grant to support the infusion of DT into courses across the curriculum.
} 
Community Design. It is more resonate with Rittner's framing of design education (2020) as a process that helps us "unpack and interrogate the ways in which reality intersects with design" (p.13) and Constanza-Chock's pedagogies for design justice (2020), than with models that focus on product design or celebratory innovation sprints.

Some have questioned the liberal arts, interdisciplinary value of DT practices (e.g., Iskander, 2018; Kolko, 2018; Vinsel, 2017; Woudhuysen, 2011). Others have rejected the idea that it is even a real thing. "Isn't this what transformational, experiential education does at its best?" Or "Isn't this a less rigorous version of the scientific method?" or "Isn't this just design done badly?" Skepticism and varying interpretations abound (Johansson-Sköldberg et al., 2013). This study addresses questions about the value of DT, while Liedtka and Bahr's research (2019) addresses the earlier critical question: Is this even a real thing? They have shown it is. Following Campbell and Fisk's conditions for construct validity (1959), they reviewed the vast array of DT literature and found uniformity among the core attributes, process, and tools used (i.e., convergence). They also found that the collective set of DT tools and methods being cited and harnessed create an "integrating framework" distinct from other methodologies (i.e., discriminant).

\section{What Does DT “Really” Do?!}

While a wide-array of academic, professional, and public literature on DT has emerged, most of these publications focus on design-based stories, projects, and short-term programs.

\section{Lessons from within Higher Education}

Not only is DT a legitimate process distinct from others, we argue it can be a powerful pedagogy for moving students beyond conducting disciplinary-bound and theory-driven research on abstract findings. In fact, we join others (Costanza-Chock, 2020; Escobar, 2017) in arguing DT can be a resource for supporting more diverse, equitable, and inclusive high impact pedagogies, including: engaged, experiential learning, critical, community based learning practices, place-, problem-, and project-based learning (Wurdinger \& Qureshi, 2015), liberatory and decolonizing pedagogies, and other high impact practices (Kuh, 2012). We also see DT practices as valuable for preparing students for their professional, civic, and personal lives.

Alongside the expansive growth of DT as a practice within and outside of higher education, academic and non-academic publications on DT have flooded the system over the past decade (Panke, 2019). For example, Royalty et al. (2014) conducted a study with d.school students from three courses (Introduction to Design Methodology; Design and Society; and an education focused course) using the Creative Agency Scale and reported gains in students' creative confidence by the end of the semester. Benson and Dresdow (2015) introduced DT into their upper level decision-making course including students with differing majors (e.g., business administration, computer science, nonbusiness). The students were challenged to create a new product and an organizational design structure to support it. At the end of the semester, students indicated they gained skills in critical thinking, creativity, and innovation. In addition, a case study for introducing a new course in design thinking to engineering students indicated the students felt they gained empathy in various contexts (Rossmann, 2016). After working with 5,000 first-year students in their three-day experiential learning program, Butler and Roberto (2018) suggest succeeding in design thinking requires paying attention to cognitive obstacles and using metacognition to recognize and overcome them. 
Many also focus on disciplinary-bound DT practices (McLaughlin et al., 2019; Micheli et al., 2019). For instance, while Wrigley and Straker's (2017) research summarizes DT pedagogies in 51 courses across institutions, they focus on business, entrepreneurship and design courses exclusively, failing to capture the use of DT pedagogies across the Humanities, Sciences, and Social Sciences. They found that these courses focused on DT differently and that these different elements could be scaffolded across programs. They ultimately recommend DT pedagogies to be helpful for producing more viable and valued outcomes; for strategizing about and overseeing effective projects and building skills valuable in students' future personal and professional endeavors.

Panke's article (2019) consolidates findings from previous literature reviews and studies, exploring the wide-ranging interpretations of DT pedagogies. She concludes DT pedagogies can support a wide variety of learning outcomes across a range of programs, supporting faculty interested in preparing students to more inclusively, creatively, resiliently address wicked problems. She finds, for instance, that these practices support transdisciplinary projects, making implicit learning tangible and embodied, relational and iterative, as well as purposeful and playful (iterating). Additional research has shown such pedagogies can move students towards generating relevant and grounded projects in and with communities (Crouch \& Pearce, 2012; Fernaeus \& Lundstrom, 2015; Krebs, 2012; Lake et al., 2017; Miller, 2015). Costanza-Chock at MIT's Civic Media Collaborative Design Studio, for instance, requires students engage DT practices in order to develop a media project intended to meet the needs of a local organization while simultaneously developing students' skills and passions. Projects vary depending on the partner and the year. In one semester this led to "modified carnival games" intended to be played in public in order to increase awareness of inequalities in the local area, educate about housing rights, and draw supporters (2020, p. 175-6). On the other hand, prior research has also shown that DT does not necessarily yield valued outcomes. For example, Ohly et al. (2017) reported students enrolled in a Design Methodology course from five different classes over one year did not self-report they were better able to generate novel and useful ideas by the end of the semester.

While some studies explore the role and impact of DT on students, few have studied faculty perceptions of DT as this study does. Retna's qualitative case study (2016) on K-12 teacher's perceptions of DT in Singapore showed that instructors felt DT practices were valuable for fostering student collaboration, creativity, and problem-solving, but that resource and time constraints along with the challenges of implementing vastly different pedagogies caused consistent challenges.

\section{Lessons beyond Higher Education}

Outside of higher education, researchers have found that DT is being applied implicitly as social entrepreneurs change agents struggle to address intractable wicked problems (Kummitha, 2018). A few large businesses have found that DT practices have positively impacted their traditional return on investment numbers (Forrester, 2018; Sheppard et al., 2018). Liedtka and Bahr's study (2019) examined DT practices across over 400 business, government, and nonprofit teams. It shows that in many cases moderate ability to engage with DT practices yields significant benefits. They found that engagement with DT practices were correlated with five key outcomes. Respondents in their study indicated these practices built trust, enhanced their ability to implement team projects, increased the quality of solutions, yielded psychological benefits, and increased network capabilities. Liedtka and Bahr (2019) 
also found that a small set of what they call "DT super practices" had a significant impact on valued outcomes; these included forming diverse teams, emphasizing active listening, executing real world experiments, and generating a diverse set of ideas. Of particular note for their study (and for ours), they found that while implementing real world experiments was one of the least used practices, it was also one of the most powerful. While their research moves the field beyond qualitative case studies towards quantifiable measures, it is important to note that it relies on self-reported use of DT practices and perceived outcomes.

In general, studies that engage larger sample sizes, address the range of practices and perceived outcomes across diverse courses, harness a mixed methods approach, and compare findings across sectors - as this study does - are still rare. We know design, done badly, can be catastrophic (Monteiro, 2019). Liedtka et al. (2021), for instance, argue that narrow commitments to design sprints and unrealistic expectations by leaders encourage shallow dips into DT practices. What DT pedagogies might best prevent these catastrophic outcomes and better prepare more ethical and inclusive changemakers? We know of no studies that have intentionally sought to compare the DT practices and outcomes unfolding in the business, government, and nonprofit sectors to what is happening within higher education.

\section{Method}

In designing this study, we incorporated this recent research on DT practices and outcomes from within higher education (Lake et al., 2019; Lake et al., 2017) and across other sectors (Liedtka \& Bahr, 2019, Liedtka 2017). We also drew upon recent research on innovative pedagogical practices in higher education (Kuh, 2012). Liedtka and Bahr's survey instrument harnesses the most up-to-date scholarship from social, for-profit, and government sectors harnessing DT (Calgren et al., 2016; Elsbach \& Stigliani, 2018; Micheli et al., 2019). This study adapts Liedtka and Bahr's survey instrument (Liedtka \& Bahr, 2019), asking instructors what DT practices they implemented in their courses and what perceived outcomes they noticed. Additional questions were constructed to include course descriptors as well as open-ended prompts to expand upon faculty experience and perceptions of DT. In order to explore participants' survey responses in greater depth, this study added semi-structured interviews with faculty.

\section{Participants}

A total of 35 faculty were recruited to voluntarily participate in this study; they included faculty who had formally (DT-focused courses, participation in faculty development trainings, grant funding requests) or informally (i.e., one to-one consulting, Director outreach efforts, etc.) connected with the DT initiative in some way (e.g., via workshops or consultations regarding their courses). All 35 faculty completed the surveys and 34 completed the optional semistructured follow up interviews. Participating faculty represented a variety of fields, including 11 from the Humanities (e.g., philosophy and english), 11 from Social Science fields (e.g., psychology and anthropology), and 14 from Professional disciplines (e.g., architecture and engineering). The responses also captured courses from the first year to graduate level, including 100 level ( $n=8), 200$ level $(n=10), 300$ level $(n=6), 400$ level $(n=8)$, and graduate level $(n=3)$ courses. Seventy-five percent of the faculty explicitly told students DT was an approach they were implementing in their course and 46 percent explicitly referenced DT in one or more learning 
outcomes for their course. On average, faculty had experience teaching the course for 2.06 years $(S D=1.11)$, with a range of one to four years. Faculty did not receive compensation for participating in the study. The study was approved by the Institutional Review Board at the university.

\section{Materials}

\section{Survey}

The survey had 41 items total and included three sections, i.e., DT Practices, Perceived Outcomes, and Supplemental Information. The first section on DT practices included nine items related to DT methodology (e.g., "students received iterative feedback from stakeholders outside of the class on their prototypes"). DT practices and outcomes were slightly modified in wording from the practices and outcomes set forth by Liedtka and Bahr (2019) so they fit within the context of curricular practices. DT practice and outcome items were rated on a 5point Likert scale ranging from: 1 (never), 2 (sometimes), 3 (about half the time), 4 (most of the time), and 5 (almost always), (Table 1). The second section on faculty perceptions of outcomes included 24 items at the team and individual level (e.g., "helped teams see the problems in new ways, resulting in solving more promising problems"). As set forth by Liedtka and Bahr (2019) five outcome subscale scores were computed from the 24 items: (1) Improved implementation and adaptation, (2) Individual psychological benefits, (3) Expanded network relationships and resources, (4) Increase solution quality, and (5) Trust building. Psychological benefits were derived from respondents' self-ratings of safety and confidence to explore ideas and take collaborative risks. Expanded network relationships and resources were derived from self-ratings indicating new relationships and resources increased the project's value and viability. It is important to note as well that trust-building included indicators between project team members as well as the project team and external stakeholders. The third section of the survey collected supplemental information such as the participants'

Table 1 Descriptive statistics for dt practice items

\begin{tabular}{|c|c|c|c|c|c|c|c|c|}
\hline DT practice items & $\mathrm{N}$ & Min & Max & Median & Mean & SD & $\begin{array}{l}95 \% \\
\text { lower } \\
\text { bound }\end{array}$ & $\begin{array}{l}95 \% \\
\text { upper } \\
\text { bound }\end{array}$ \\
\hline $\begin{array}{l}\text { Work in teams that recognized diverse } \\
\text { contributions }\end{array}$ & 35 & 2.00 & 5.00 & 4.00 & 4.09 & 1.01 & 3.74 & 4.43 \\
\hline $\begin{array}{l}\text { Engage in active listening among team members in } \\
\text { order to find shared meaning. }\end{array}$ & 35 & 1.00 & 5.00 & 4.00 & 3.80 & 1.05 & 3.44 & 4.16 \\
\hline $\begin{array}{l}\text { Create prototypes of their ideas (e.g., storyboards, } \\
\text { videos, mock-ups, etc.) }\end{array}$ & 33 & 1.00 & 5.00 & 3.00 & 3.27 & 1.35 & 2.79 & 3.75 \\
\hline $\begin{array}{l}\text { Create a set of design criteria that described an } \\
\text { ideal solution, based on research }\end{array}$ & 35 & 1.00 & 5.00 & 3.00 & 3.11 & 1.37 & 2.64 & 3.58 \\
\hline $\begin{array}{l}\text { Identify a problem definition based on people's } \\
\text { perspective rather than on theory or } \\
\text { organizational perspectives alone }\end{array}$ & 35 & 1.00 & 5.00 & 3.00 & 3.00 & 1.24 & 2.58 & 3.42 \\
\hline Move multiple ideas into prototyping and testing & 35 & 1.00 & 5.00 & 2.00 & 2.74 & 1.42 & 2.25 & 3.23 \\
\hline Execute real world projects to test the ideas & 35 & 1.00 & 5.00 & 2.00 & 2.71 & 1.49 & 2.20 & 3.22 \\
\hline Engage in research using ethnographic tools & 35 & 1.00 & 5.00 & 2.00 & 2.69 & 1.32 & 2.23 & 3.14 \\
\hline $\begin{array}{l}\text { Receive iterative feedback from stakeholders } \\
\text { outside of the class on their prototypes }\end{array}$ & 35 & 1.00 & 5.00 & 2.00 & 2.51 & 1.27 & 2.08 & 2.95 \\
\hline
\end{tabular}


department, level of current course, and their DT expertise, including classifications of 1 (no experience), 2 (limited), 3 (moderate level), and 4 (extensive experience). Participants were also asked if DT was explicitly stated on the syllabus and whether students completed a real world project in the course. Open ended survey questions asked participants about additional DT practices they implemented, what negative or positive outcomes they perceived, and if there were additional supports they could use.

\section{Semi-Structured Interview}

The semi-structured interview protocol was adapted from Lake et al. (2018). It was designed to clarify survey findings, further understand the pedagogical aims of implementing DT, the challenges encountered, the perceived outcomes, and any additional support faculty might value having in the future.

\section{Procedure}

\section{Survey}

Faculty were invited to participate by email. The online survey started with an informed consent for participants to read and then provide an electronic signature indicating consent. After reading the survey instructions, all 35 participants completed the three survey subsections, taking anywhere between 7 to 20 minutes to complete.

\section{Semi-Structured Interview}

Survey respondents were invited to complete the optional follow-up interview at the completion of the survey. Semi structured interviews ranged from 25-60 minutes in length. All 34 interviews were conducted via WebEx by the primary investigator and, when possible, one other team member.

\section{Analyses}

\section{Survey}

Each DT practice and outcome item rating distribution was examined for normality, skew, and kurtosis. The assumptions for parametric statistics were met, with Pearson correlation coefficients computed to examine relationships between variables and independent t-tests to identify mean differences between groups. Given the exploratory nature of this study, we set $a=.10$.

\section{Semi-Structured Interview}

Automated transcriptions were edited by team members verbatim to ensure accuracy. Braun and Clarke's approach to thematic analysis (Braun \& Clark, 2006) was used to identify codes and themes. Each researcher worked independently with each transcript to specify codes. The research team then compared codes, discussed extracted themes, ultimately aligning themes and modifying codes as necessary. 


\section{Results}

\section{RQ 1: DT Practices}

All of the practices were used by the faculty with means ranging from 2.51 (some of the time) to 4.09 (most of the time), (Table 1). The two DT practices faculty gave the highest ratings for utilizing involved teamwork: specifically (1) "work in teams that recognize diverse contributions" $(M=4.09)$, and (2) "engage in active listening in order to find shared meaning" $(M=3.80)$. In contrast, the two DT practices that faculty rated the lowest for utilization involved new skill sets for students including engagement with different stakeholders: specifically (1) "engage in research using ethnographic tools" $(M=2.69)$, and (2) "receive iterative feedback from stakeholders outside of the class on their prototypes" $(M=2.51)$.

\section{RQ 2: Outcomes}

Faculty's average ratings for all five outcomes ranged from 3.26 (about half the time) to 3.98 (nearly, most of the time), (Table 2).

\section{RQ 3: DT Practice and Outcome Relationships}

We found a negative correlation between certain DT practices and outcomes. First, results indicated there was a significant negative relationship between the "practice of engaging in ethnographic tools" and the subscale "expanding network relationships and resources" $(r(31)=$ $-.47, p=.003)$. Second, there was a significant negative relationship between the "practice of creating design criteria to find an ideal solution" and the subscale "trust building" $(r(31)=-.31$, $p=.044)$.

\section{Individual Differences: Disciplines, Course Level, and DT Experience}

In order to assess the role of disciplinary frames or course levels or faculty's DT experience on DT practices and outcome subscales, additional analyses are reported.

\section{Disciplinary Frames}

Faculty in the Professional Schools gave significantly higher ratings for the DT practice "creating prototypes" $(M=3.77)$ compared to Humanities $(M=2.67), t(20)=1.94, p=.066$ and

Table 2 Descriptive statistics for DT outcomes

\begin{tabular}{|c|c|c|c|c|c|c|c|c|}
\hline DT outcomes & $\mathrm{N}$ & Min & Max & Median & Mean & SD & $95 \%$ lower bound & $\begin{array}{l}95 \% \text { upper } \\
\text { bound }\end{array}$ \\
\hline Quality of solutions generated & 34 & 2.33 & 5.00 & 4.00 & 3.98 & 0.70 & 3.73 & 4.22 \\
\hline Individual Psychological Benefits & 30 & 1.00 & 5.00 & 4.00 & 3.85 & 0.92 & 3.51 & 4.20 \\
\hline $\begin{array}{l}\text { Improved Implementation and } \\
\text { Adaptation }\end{array}$ & 34 & 1.88 & 5.00 & 4.00 & 3.80 & 0.85 & 3.51 & 4.10 \\
\hline Trust Building & 32 & 1.00 & 5.00 & 3.50 & 3.42 & 1.15 & 3.01 & 3.84 \\
\hline $\begin{array}{l}\text { Expanded network relationships } \\
\text { and resources }\end{array}$ & 32 & 2.00 & 5.00 & 3.00 & 3.26 & 0.96 & 2.91 & 3.60 \\
\hline
\end{tabular}


the DT practice "moving multiple ideas into testing" $(M=3.23)$ compared to Humanities $(M=2.00), t(21)=2.11, p=.047$.

There were two significant findings between disciplinary frames for DT outcomes. The faculty in Humanities gave higher ratings for the outcome subscale "trust building" $(M=3.90)$ compared to Social Sciences $(M=3.04), t(20)=1.99, p=.059$. Humanities faculty also gave significantly higher ratings for the outcome subscale "improved implementation and adaptation" $(M=4.20)$ than the Professional Schools $(M=3.64)$, $t(20)=1.92, p=.070$.

\section{Course Level}

Comparing practices by course level, faculty teaching 100 level courses gave significantly higher ratings for "creating prototypes" $(M=4.00)$ compared to faculty teaching 200 level courses $(M=2.44), t(13)=2.26, p=.042$; there was also a significant difference for this practice between 200 vs. 300 level courses $(M=4.17), t(13)=3.26, p=.006$. The practice "move multiple ideas to testing" showed a significantly higher rating for 300 level courses $(M=3.67)$ compared to 200 level courses $(M=2.30), t(14)=2.05, p=.060$. Finally, faculty teaching 100 level courses rated the practice "create design criteria" $(M=4.00)$ higher than faculty teaching 400 level courses $(M=2.67), t(14)=2.02, p=.063$. While the DT practices being practiced varied widely, perceived outcomes did not significantly differ by course level.

\section{Faculty Experience}

The sample sizes were sufficient to compare faculty with a self-perceived moderate level of experience $(n=19)$ compared to faculty who felt they had limited experience $(n=8)$ for DT practices and outcomes. Faculty with a moderate level of experience gave significantly higher ratings for "creating prototypes" $(M=3.39)$ compared to faculty teaching with limited experience $(M=2.25), t(24)=2.19, p=.038$. Perceived outcomes did not significantly differ by faculty experience.

\section{Additional Survey Findings}

Additional questions also revealed that faculty largely perceive themselves to be novice and intermediate DT practitioners that are encountering consistent challenges (with 34\% of faculty respondents self-reporting they have only limited experience with DT pedagogies, 54\% reporting moderate experience, and $12 \%$ reporting extensive experience).

Over $70 \%$ of participants required students use the DT process on a "real world" project. When asked to describe these projects, participants described a range of projects from on-campus mental health campaigns, to the creation of marketing materials for offcampus clients, to intervention projects for problems encountered while in clinical rotation. Faculty indicating they were not requiring "real world" projects also described a range of creative and relevant projects: from asking students to create a "hypothetical artsbased business plan," to a dream job vision board, to philosophical games they could play with others outside the class.

Table 3 summarizes negative outcomes noted by faculty, indicating a desire for a community of practice where they could learn from one another, share DT tools and methods, and gain confidence in their abilities to utilize DT practices in their courses. 
Table 3 Open ended survey findings

\begin{tabular}{lll}
\hline Additional Pedagogical tools & Perceived negative outcomes & Support requested \\
\hline Agile/Scrum & Student frustration with ambiguity & Community of practice \\
Facilitation techniques & Resistance to non-linear process & Additional DT tools \\
Systems change processes & Lack of trust in the process & Professional development \\
Decision-making tools & Time constraints & More time \\
& Anxiety about outcomes & More space \\
\hline
\end{tabular}

\section{Initial Interview Findings}

\section{Similarities across Disciplines: DT Goals, Experiences, \& Challenges}

In general, the interviews revealed the goals for integrating DT practices into faculty courses were somewhat consistent across diverse disciplines. Faculty offered an array of similar reasons for implementing DT, such as giving their students a toolkit or preparing them for post-graduate life.

Faculty across disciplines noted similar challenges to implementing DT practices and reflected findings from the survey. Specifically, faculty mentioned difficulties around the emergent, organic nature of DT practices assessment, and deadlines. They indicated students felt overwhelmed, stressed, and challenged to engage with DT practices at various points in the semester. As one faculty member said, "I think their [student] anxiety keeps them from genuinely going into it and putting all of their creativity into it as much... a lot of them are inexperienced with having to create something that then they're responsible... transferring ideas into something real... I think that it's kind of anxiety producing for them." Some faculty discussed how they experienced difficulty convincing students to 'buy in' to DT. One saying, "It gets overwhelming quickly to them because you begin to see how big, how messy, how complicated it is."

Professors also expressed frustration and confusion over how to structure their courses under the time constraints of a single semester and how to assess their students' work. Anxiety around the messy, risky nature of DT pedagogies and stress about how students would evaluate the course on end-of-semester evaluations was also consistently noted across faculty participants. One interview said, "I've been lucky that my dean understands that design thinking often achieves results over a long period of time." Another interviewee said "[my colleague] and I have been doing this by the seat of our pants because we sincerely believe that this is the right way to prepare our students to be successful after college. And we have taken significant heat throughout the years because the student course evaluations at the end of the semester are often not complimentary." Indeed, when asked what negative outcomes they observed from infusing DT pedagogies, 10 of the 14 survey participants said student critiques (e.g., frustration, lack of support, etc.). In addition, while novice DT practitioners said they struggled to accurately assess the outcomes of their course, more experienced faculty noted "the more you teach, the more you're clear about your objectives and the more you talk about them. You know that they are actually getting something out of it." Another faculty member said their hope is that students will realize the benefits to them over the long term even "if they don't realize it at the time." As another experienced DT practitioner said, "I have a lot of resources in my back pocket." Indeed, three more experienced faculty indicated that these practices enhanced their student evaluations. 


\section{Differences across Disciplines: Valuing \& Neglecting Different Parts of the Process}

While faculty across disciplines articulated similar goals and challenges, interview analysis revealed that faculty from different disciplines were likely to value some aspects of the process more highly than others. Faculty tended to define DT in part through their disciplinary training. For a Humanities faculty member, DT was, "kind of repackaging what we've always talked about." For a Social Science faculty member, DT was a "very similar process to the scientific method and the way we do research in general." A Professional School faculty member described DT as, "a process for workflow or project management... a process for problem solving and developing resolutions." As in the surveys, prototyping was a topic of discussion for many of the faculty for how to engage students and assess.

Unsurprisingly, disciplinary lenses also influenced how faculty implemented DT practices in their courses. For instance, faculty from different fields took vastly different approaches to prototyping. Many, particularly those in the Humanities, expressed confusion and concern over prototyping. For one Humanities professor, prototyping "is actually like physically designing something." While another professor simulated a project management meeting as a form of prototyping by asking students to "write out a plan" and "poke holes in it" in order to "write a new plan." Many faculty indicated they allocated most of their time in the empathizing, defining, and brainstorming stages of DT (i.e., "spent most of the time on framing: falling in love with the right questions"). While this might contribute to shared meaning for teams, it can delay needed opportunities to have assumptions challenged through prototyping. There were also key differences across disciplines regarding how DT practices impacted students' experiences of inclusivity, communication, and collaboration. For instance, some of the Social Sciences professors stressed how they valued the inclusivity of diverse perspectives in DT and discussed how this process fostered inclusivity in their classes. In their interviews, some touched on how they would purposefully construct well rounded project groups or encourage quiet or less active students to speak. Faculty participants from the Professional Schools did not focus on these aspects of DT, but instead frequently mentioned improvements in student ownership of their own ideas or the incorporation of stakeholders' perspectives and opinions.

\section{Discussion}

The mixed-method design for this study revealed both quantitative and qualitative findings informing the literature regarding DT practices and outcomes. While the survey findings were consistent with the interview results, qualitative analyses revealed new insights regarding DT practice, outcomes, and their relationships as reported by faculty in higher education.

\section{RQ 1: What DT Practices Are Being Implemented?}

The most frequently used DT practices were those that align with a traditional liberal arts undergraduate education: "Work in teams that recognized diverse contributions" and "engage in active listening among team members in order to find shared meaning"; these DT practices are essential for completing real world projects and have not been given as much attention as they deserve within DT research (Liedtka \& Bahr, 2019). The least used DT practices included "engage in research using ethnographic tools" and "receive iterative feedback from stakeholders outside of the class on their prototypes." We recognize that both practices require effort 
to engage with stakeholders outside of a course and run counter to still dominant educational paradigms that value textual analysis, theoretical study, and short-term, singular assignments over relational and iterative learning processes completed over longer periods of time through a substantive project. Over a decade of researching DT practices and outcomes has led Liedtka et al. (2021) to conclude that genuinely valuable and viable outcomes can only emerge through investing more fully in the process. In fact, Liedtka et al. (2021) refer to this as DT's "social technology."

While Liedtka and Bahr (2019) found no statistically significant differences in DT practices across their business, government, and nonprofit respondents, we found that faculty in the Professional Schools were requiring students to engage in far more prototyping and testing than their colleagues in the Humanities, but struggled more to support collaborative, team building efforts, empathetic listening, and ideation. For instance, while Professional School faculty described prototyping as a "critical way to get feedback from your end user" and an "essential feedback loop;" they also talked about collaborative group projects as "inherently problematic" with "group dynamics" getting "in the way of the process." In contrast, we found that Social Science and Humanities faculty required students to spend more time engaging in empathetic listening, collaborative ideation, and analysis, but only rarely required students engage in iterative prototyping. Humanities faculty were challenged by the notion that prototypes should be "tactile" and "tangible" when student projects were focused on dialogue and policy change. One Humanities faculty member highlighted prototyping as a practice of failing and learning in dialogue, saying their first commitment was to "cultivating a learning culture." In many ways, these findings are not that surprising. We speculate disciplinary training, departmental requirements, and professional expectations contribute to these findings. As Rittner (2020) points out, the Social Sciences specialize in critique while design fields tend to focus on "uncritical making" (p. 13). The emphasis on action and making in the Professional Schools reflects typical course requirements for students such as education students creating teaching plans or exercise science students working on a cross-campus wellness campaign. These findings indicate disciplinary blind spots that forestall the opportunity for more impactful learning. For instance, the Professional School courses may benefit from increasing efforts to build trust across teams and Humanities courses could more fully explore iterative makingto-learn practices. These findings also highlight the potential value of harnessing DT as a process for professional development that visualizes disciplinary blindspots and potentially harmful professional practices.

We also discovered it was challenging for faculty across disciplines and experience levels to fully engage students with the DT process through real world stakeholders. Systemic and procedural barriers included a lack of training, time, infrastructural support, and access. One faculty member said that even though "we discuss it and we grade on it and we do all of these other things for students to get the confidence to go to somebody who might be the most directly affected," they continually struggled with getting "students to think about who stakeholders would be." Another faculty noted that, "it just takes time... building relationships with people in the community, laying the groundwork... it's not an easy 'let me just throw it in one day' activity." Limitations of semester timelines and course hours can hamper DT practices such as making, testing, and iterating.

Despite these challenges, we found that faculty with DT experience were far more likely to provide students with making opportunities and require early testing of low fidelity prototypes compared to faculty new to DT pedagogies. This insight was repeated in the interviews, providing further validation. Whereas a faculty member newer to DT pedagogies said "we're 
not going to get past the generate phase and, as creative as I can be with this project, I don't know if that will ever change," another more experienced DT faculty member reframed this issue, saying that while, "it's [been] hard," students can "draft the details," "describe it to someone, and then, [gain] feedback." In fact, this more experienced faculty member said the iterative process was essential for helping students "see how difficult and how complex the problems are." Another experienced faculty member highlighted this same point, noting that "prototyping workshops, tools, and resources" were crucial for "building the maker mindset."

One of the values of the DT process is its commitment to iterative implementation. Liedtka and Bahr (2019) also found that their respondents across sectors were underutilizing the "back end" of the DT process (i.e., not prototyping, testing, and iterating as much). They suggest that paying more "attention to some of the lesser used, but critical practices in DT's testing-focused back end" could "trigger more significant value." According to Liedtka et al. (2021), "DT acts like a form of change management when it engages implementers in activities like prototyping and testing that build enthusiasm and ownership of new solutions" (p. 5). Making and testing in relationship with others motivates a willingness to persevere. Failure to harness this aspect is a disservice to students and the real world projects they are working on.

When considering the course level for the faculty's ratings for DT practices and outcomes, the most revealing finding was 200 level courses which were rated lower for practicing prototyping and moving ideas to testing compared to 100 or 300 level courses. Developmentally the 200 level courses often transition the student from beginner to intermediate, creating a situation where content delivery gains priority while DT practices may be considered secondary. This finding reinforces the point that DT practices in academia need to be considered alongside developmental learning outcomes within specific disciplines.

\section{RQ 2: What Outcomes Are Being Perceived?}

Faculty provided ratings indicating all outcomes were seen in their courses from half to most of the time, which is consistent with ratings reported by Liedtka and Bahr (2019). High ratings for outcomes such as "quality of solutions" and "trust building" by faculty would be expected given they design their courses in order to achieve specific learning outcomes. However, Humanities placed higher ratings for trust building compared to the Social Sciences, which may be linked to how teamwork was managed in their respective courses. Faculty across disciplines and experience levels shared they would like additional opportunities to learn from one another and share DT tools and methods. Creating interdisciplinary faculty learning communities makes it possible to learn when, how, and why different outcomes may be utilized across disciplines. This recommendation aligns with survey findings showing that the most highly requested resource was some form of academic support (from building their repertoire of DT practices through easily accessible, curated resources, to learning what others are doing through cross-departmental communities of practice, to more facilitated workshops and consultations).

\section{RQ 3: What Is the Relationship between DT Practices and Perceived Outcomes?}

\section{The Demands of Social Technology, the Pain of Being Wrong: Adverse Impacts}

Our findings reinforce Liedtka and Bahr's conclusion (2019), indicating a need to focus on the "social technologies" inherent in the DT process. We found that practices where students were 
required to seek feedback (like ethnographic research and the testing of prototypes) negatively impacted the relationships within the course and across stakeholder groups. We also found that generating design criteria in order to describe ideal solutions challenged efforts towards trustbuilding within teams and across stakeholders involved in the class. We speculate that these findings are due in large part to the pain experienced when initial assumptions are challenged, biases confronted, and prototypes critiqued via stakeholder feedback (whether from fellow students, the faculty, community partners, course clients, or other stakeholders). An experienced DT faculty member said, "prototyping is one of the things that our students struggle with the most in terms of this process. They can spend six weeks thinking about something and not actually doing it." The developmental readiness of various students for such challenges is a likely contributor. As another faculty member said, "a lot of students are inexperienced with having to create something that they're responsible for... transferring ideas into something real; it's anxiety producing." Another described the process as "equal parts freeing but at the same time it's terrifying" for students. Exacerbating this challenge, faculty and students are additionally faced with the constraints of imposed semesterly timelines. These findings further reinforce the potential value of infusing and scaffolding DT practices across the curriculum.

Both of these practices (i.e., ethnography and design criteria) require skills students may not feel very confident about within the context of completing a high stakes project within a singular course and semester. As another DT faculty member noted, "It gets overwhelming quickly to them because you begin to see how big, how messy, how complicated it is." This lack of confidence is likely to be more acute with face-to-face interactions such as interviewing. These findings fortify earlier findings about the need to move beyond "a piecemeal approach towards curriculum redesign" and consider how to address resource and time constraints (Retna, 2016, p. 5). Butler and Roberto (2018) highlight why both students and seasoned executives struggle with the methodology and why valued outcomes may not be attained. They offer six countermeasures at each stage of the design thinking process for such "cognitive traps." They suggest, for instance, that the fundamental attribution error and resistance to feedback can be overcome by exploring what others like about a solution before moving to critical feedback.

Interestingly, Liedtka and Bahr (2019) reported similar negative relationships with ethnography and outcomes when controlling for variables such as organization type and experience. In particular, they found that ethnographic research had negative psychological impacts and that it hampered practitioners' "interest in and ability to sustain collaboration" (p. 12). Liedtka's earlier studies (2015) align with our findings, leading her to conclude that DT processes are valuable for reducing cognitive bias and that having our own world views challenged by others is painful. Indeed, the role of emotions such as discomfort, distress, surprise, and delight within the DT process is an area of interest worthy of future study (Elsbach \& Stigliani, 2018; Vink, 2019). We note that the widely varying understandings of ethnographic research, alongside its contested nature, contributed to this finding. As Liedtka and Bahr (2019) also point out, we hypothesize that the strain of coming to a shared vision for a collaborative project under tight semesterly deadlines challenges efforts towards building trust. The challenges of coursespecific, semester-long project-based learning and the need to build in iterative longer-term opportunities has been noted by other researchers (Wurdinger \& Qureshi, 2015). We recommend curricular designers take the "social technologies" of DT (as a relational, project-based innovation process) more directly into account, building in more time and structures for creating and sustaining relationships of trust, seeking feedback across systems, iterating on designs and prototypes, and reflecting on the embodied praxis of the work. 


\section{Limitations \& Future Directions}

The sample for this study was limited to faculty connected to the Center for DT in some capacity. Therefore, the findings may not extend to other faculty at the university or other institutions. The survey included items reworded from Liedtka and Bahr's survey (2019) for both DT practice and DT outcomes. Therefore, the computation of the outcome subscales based on their factor analysis assumes our word changes would not have produced widely divergent constructs. As with any selfreport survey, it is important to note the facultys' ratings reflect their perceptions of utilizing DT practices and setting forth outcomes. Faculty perceptions may not be consistent with student perceptions and this study did not address changes across the semester. It was not possible to survey stakeholders involved in the course projects, but their perceptions would also provide another point of view regarding the implementation of DT practices and outcomes. Longitudinal cross-institutional research of DT practices and outcomes with faculty, students, and stakeholders is currently underway enabling us to expand and diversify the sampling and gain additional insights that further verify or complicate these findings.

\section{Conclusion: Emerging Themes for Transforming Higher Education}

This study revealed that faculty across disciplines, and with a range of experience levels, overwhelmingly believe DT pedagogies yield a long list of valued outcomes for their students. We found that the DT practices emerging from a liberal arts curriculum across disciplines are encouraging students to engage in and with DT "super practices"- those that have been shown to have a powerful impact on valued outcomes: like forming diverse teams, emphasizing active listening, and executing real world experiments (Liedtka, 2017; Liedtka \& Bahr, 2019).

This study simultaneously highlighted a variety of challenges faculty faced in trying to implement DT pedagogies. We found that some challenges were prompted by and persisted because of disciplinary blindspots (e.g., some faculty focused on empathetic listening, while others emphasized prototyping to the detriment of deep listening); other challenges were quickly ameliorated with moderate experience (e.g., supporting project-based learning); and yet other challenges were omnipresent (e.g., finding time to iterate, opening opportunities to engage with diverse communities, etc.).

In general, DT, as a curricular strategy, should not be characterized as a quick and easy pedagogical technique that will yield immediate improvements in learning processes and products. Instead, it should be recognized as a flexible method and process for developing the capacities to accept critical feedback, cope with ambiguity, and develop the trust necessary for inclusive and equitable risk-taking. These challenges highlight how many higher educational structures (disciplinary silos), processes (credit-hours and semester timelines), and cultures (individualized expertise and the privileging of scholarly, disembodied knowledge) create barriers to effective DT practices.

To address these challenges, we recommend a range of strategies:

- Institutional support for faculty training, especially opportunities that encourage crossdisciplinary communities of practice and mentoring which move beyond piecemeal workshops and on-line modules which are critical for professional development.

- Faculty and administrative advocacy efforts designed to create more flexible educational structures, processes, and cultures are needed. Such efforts should encourage more collaborative and intentional project-based opportunities across students' program of study 
(e.g., create structures and processes that encourage relationships of trust, require feedback across space and time, and prompt iteration on designs and prototypes). We recommend those looking to build student capacities and increase the value and viability of student projects look to peer-to-peer mentoring programs, mentor and journey mapping tools, living-learning communities (Inkelas et al., 2018), learning lab models (Crosby et al., 2018; Verhoef, 2020), engaged department initiatives (Lake et al., 2019), and other diverse cross-course and community-campus collaborative processes for inspiration.

- The creation and utilization of longitudinal assessment metrics that acknowledge and value the challenges of emergent, relational, iterative project-based learning across stakeholder groups (including student, faculty, and community partners) should be implemented. It is important for faculty to be able to identify necessary course modifications by tracking the outcomes of their course through multiple touchpoints. Faculty need to be prepared to iterate, iterate, and iterate their own DT practices within a course. We suggest administrators support these opportunities and invest both time and resources to put in place assessment practices for faculty, students, and partners to reflect on the challenges and the merits of DT.

In the end, this study visualizes the value of liberal arts undergraduate curriculum while simultaneously pointing to innovative opportunities to reimagine curriculum so that it may better prepare graduates for the world they face ahead.

Acknowledgement We want to thank Elon faculty for their willingness to participate in this research project. We were inspired by their commitment to engaged, experiential, and relational learning and are grateful to share their wisdom with our readers.

Funding No special funding was awarded for this research. Danielle Lake is employed by the institution participating in this study and Morgan Kearns is an undergraduate research assistant at this same institution.

\section{Compliance with Ethical Standards}

Conflicts of Interest/Competing Interests Danielle Lake, one of the researchers, is the Director of Design Thinking at the institution where the study took place.

Ethics Approval Elon by Design: Assessing Elon's Design Thinking Ecosystem has been verified by the Elon University Institutional Review Board as Exempt according to 45CFR46.101(b)(2): (2) Tests, Surveys, Interviews on $12 / 08 / 2019$. The protocol is $20-148$. The procedures used in this study adhere to the tenets of the Declaration of Helsinki.

Consent to Participate In alignment with Elon's Institutional Review Board requirements, study participants consented to participate prior to completing the survey instrument. Study participants were given the option to elect into a follow-up interview before completing the survey.

Consent for Publication The consent form for participation in the study noted the intent by researchers' to publish findings in a peer reviewed journal.

Open Access This article is licensed under a Creative Commons Attribution 4.0 International License, which permits use, sharing, adaptation, distribution and reproduction in any medium or format, as long as you give appropriate credit to the original author(s) and the source, provide a link to the Creative Commons licence, and indicate if changes were made. The images or other third party material in this article are included in the article's Creative Commons licence, unless indicated otherwise in a credit line to the material. If material is not included in the article's Creative Commons licence and your intended use is not permitted by statutory regulation or exceeds the permitted use, you will need to obtain permission directly from the copyright holder. To view a copy of this licence, visit http://creativecommons.org/licenses/by/4.0/. 


\section{References}

Benson, J., \& Dresdow, S. (2015). Design for thinking: Engagement in an innovation project. Decision Sciences Journal of Innovative Education, 13(3), 377-410. https://oi.org/10.1111/dsji.12069

Braun, V., \& Clark, V. (2006). Using thematic analysis in psychology. Qualitative Research in Psychology, 3(2), 77-101. https://doi.org/10.1191/1478088706qp063oa

Brodie, R. J. (2014). Future of theorizing: Increased contribution by bridging theory and practice. In L. Moutinho, E. Bigne, \& A.K. Manrai (Ed.), The Routledge companion to the future of marketing (pp. 88104). Routledge.

Brown, T. (2009). Change by design: How design thinking transforms organizations and inspires innovation. Harper Collins Publishers.

Butler, A.G., \& Roberto, M.A. (2018). When cognition interferes with innovation: Overcoming cognitive obstacles to design thinking. Research-Technology Management, 61(4), 45-51. https://doi.org/10.1080/ 08956308.2018.1471276

Calgren, L., Elmquist, M., \& Rauth, I. (2016). The challenges of using design thinking in industry-experiences from five large firms. Creativity and Innovation Management, 25(3), 344-362. https://doi.org/10.1111/caim.12176

Campbell, D. T., \& Fiske, D. W. (1959). Convergent and discriminant validation by the multitrait-multimethod matrix. Psychological Bulletin, 56(2), 81-105.

Costanza-Chock, S. (2020). Design justice: Community-led practices to build the worlds we need. MIT Press. https://doi.org/10.7551/mitpress/12255.001.0001

Crosby A., Fam D., \& Mellick Lopes A. (2018) Transdisciplinarity and the 'living lab model': Food waste management as a site for collaborative learning. In D. Fam, L. Neuhauser, \& P. Gibbs (Eds.) Transdisciplinary theory, practice and education (pp. 117-131. Springer, Cham. https://doi.org/10.1007/ 978-3-319-93743-4_9

Crouch, C. \& Pearce, J. (2012). Doing research in design. Berg Publishers.

Elsbach, K.D., \& Stigliani, I. (2018). Design thinking and organizational culture: A review and framework for future research. Journal of Management, 44(6), 2274-2306. https://doi.org/10.1177/0149206317744252

Escobar, A. (2017). Designs for the pluriverse: Radical interdependence, autonomy, and the making of worlds. Duke University Press.

Fernaeus, Y., \& Lundstrom, A. (2015). Practicing design judgement through intention-focused course curricula. Design and Technology Education: An International Journal, 20(1), 47-58.

Forrester Research Inc. (2018). The total economic impact of IBM's Design Thinking Practice. Retrieved from https://www.ibm.com/downloads/cas/Z4WBDR8Q

Inkelas, K. K., Jessup-Anger, J., Benjamin, M., \& Wawrzynski, M. R. (2018). Living-learning communities that work: A research-based model for design, delivery, and assessment. Stylus Publishing, LLC.

Iskander, N. (2018). Design thinking is fundamentally conservative and preserves the status quo. Harvard Business Review Digital Articles, 1-9.

Johansson-Sköldberg, U., Woodilla, J., \& Çetinkaya, M. (2013). Design thinking: Past, present and possible futures. Creativity and Innovation Management, 22(2), 121-146. https://oi.org/10.1111/caim.12023

Kolko, J. (2018). The divisiveness of design thinking. Interactions, 25(3), 28-28. https://doi.org/10.1145/ 3194313

Krebs, P. M. (2012). Next time, fail better. Chronicle of Higher Education, 58(36), A60.

Kuh, G.D. (2012). High-impact educational practices: What they are, who has access to them, and why they matter. Peer Review, 14(3), 29.

Kummitha, R.K.R. (2018). Institutionalising design thinking in social entrepreneurship: A contextual analysis into social and organizational processes. Social Enterprise Journal, 14(1), 92-107. https://doi.org/10.1108/ SEJ-12-2016-0059

Lake, D., Lehman, M., \& Chamberlain, L. (2019). Engaging through design thinking: Catalyzing integration, iteration, innovation, and implementation. eJournal of Public Affairs, 8(1), 87-113. https://doi.org/10.21768/8.1.5

Lake, D., Mileva, G., Carpenter, H., Carr, D., Lancaster, P., \& Yarbrough, T. (2017). Shifting engagement efforts through disciplinary departments: A mistake or a starting point? A cross-institutional, multi-department analysis. Journal of Higher Education Outreach and Engagement, 21(3), 135-164.

Lake, D., Ricco, M., \& Whipps, J. (2018). Design thinking accelerated leadership: Transforming self, transforming community. The Journal of General Education, 65(34), 159-177.

Liedtka, J. (2015). Perspective: Linking design thinking with innovation outcomes through cognitive bias reduction. Journal of Product Innovation Management, 32(6), 925-938. https://doi.org/10.1111/jpim.12163

Liedtka, J. (2017). Evaluating the impact of design thinking in action. Academy of Management Proceedings, 2017(1), 1-6. https://doi.org/10.5465/AMBPP.2017.177

Liedtka, J., \& Bahr, K.J. (2019). Assessing design thinking's impact: Report on the development of a new instrument . Darden Working Paper Series No. 19-13. University of Virginia: Darden School of Business. 
Liedtka, J., Hold, K., \& Eldridge, J. (2021). Experiencing design: The innovator's journey. Columbia Business School Publishing.

McLaughlin, J. E., Wolcott, M. D., Hubbard, D., Umstead, K., \& Rider, T. R. (2019). A qualitative review of the DT framework in health professions education. BMC Medical Education, 19, 98. https://doi.org/10.1186/ s12909-019-1528-8

Micheli, P., Wilner, S. J., Bhatti, S., Mura, M., \& Beverland, M.B. (2019). Doing design thinking: Conceptual review, synthesis and research agenda. Journal of Product Innovation Management, 36(2), 124-148. https:// doi.org/10.1111/jpim.12466

Miller, P.N. (2015, April 3). Is 'design thinking' the new liberal arts? Chronicle of Higher Education, 61 (29), 1.

Monteiro, M. (2019). Ruined by design: How designers destroyed the world, and what we can do to fix it. Mule Design.

Ohly, S., Plückthun, L., \& Kissel, D. (2017). Developing students' creative self-efficacy based on design thinking: Evaluation of an elective university course. Psychology Learning and Teaching, 16(1), $125-132$.

Panke, S. (2019). Design thinking in education: Perspectives, opportunities, and challenges. Open Education Studies, 1(1), 281-306. https://doi.org/10.1515/edu-2019-0022

Retna, K. (2016). Thinking about "design thinking": A study of teacher experiences. Asia Pacific Journal of Education , 37(1), 5-19.

Rittner, J. (2020). Design education reform: Modeling equity and inclusion in teaching and learning. Design Management Review, 31(3), 12-22. https://doi.org/10.1111/drev.12236

Rossmann, J.S. (2016). Engineering design as a liberal art: A first-semester introduction to design thinking. International Journal of Engineering Education, 32(3), 1502-1507.

Royalty, A., Oishi, L.N., \& Roth, B. (2014). Acting with creative confidence: Developing a creative agency assessment tool. In L. Leifer, H. Plattner, \& C. Meinel (Eds.), Design thinking research: understanding innovation (pp. 79-96). Springer, Cham. https://doi.org/10.1007/978-3-319-01303-9_6

Seidel, V., \& Fixson, S. (2013). Adopting “design thinking” in novice multidisciplinary teams: The application and limits of design methods and reflexive practices. Journal of Product Innovation Management, 30 (1), 19-33. https://doi.org/10.1111/jpim.12061

Sheppard, B., Kouyoumjian, G., Sarrazin, H., \& Dore, F. (2018). The business value of design. Retrieved from https://www.mckinsey.com/businessfunctions/mckinsey-design/our-insights/thebusiness-value-of-design

Verhoef, L.A. et al. (2020) Towards a learning system for university campuses as living labs for sustainability. In W. Leal Filho et al. (Eds.), Universities as Living Labs for Sustainable Development. World Sustainability Series (pp. 135-149). Springer, Cham. https://doi.org/10.1007/978-3-030-15604-6 9

Vink, J. (2019). In/visible - conceptualizing service ecosystem design [Doctoral Dissertation, Karlstad University, Karlstad, Sweden]. Retrieved from http://www.diva-portal.org/smash/record.jsf?pid=diva2\% 3A1313628\&dswid=7161

Vinsel, L. (2017). Design thinking is kind of like syphilis-it's contagious and rots your brains. Unpublished manuscript. Virginia Tech.

Wagoner, M. (2017). Technology against technocracy: Toward design strategies for critical community technology [Master's Thesis, Massachusetts Institute of Technology, Cambridge, MA]. Retrieved from https://dspace.mit.edu/handle/1721.1/111297

Woudhuysen, J. (2011). The craze for design thinking: Roots, a critique, and toward an alternative. Design Principles and Practices: An International Journal, 5(6), 235-248. https://doi.org/10.18848/1833-1874/cgp/ v05i06/38216

Wrigley, C., \& Straker, K. (2017). Design thinking pedagogy: The educational design ladder. Innovations in Education and Teaching International, 54(4), 374-385. https://doi.org/10.1080/14703297.2015. 1108214

Wurdinger, S., \& Qureshi, M. (2015). Enhancing college students' life skills through project based learning. Innovative Higher Education, 40(3), 279-286. https://doi.org/10.1007/s10755-014-9314-3

Publisher's Note Springer Nature remains neutral with regard to jurisdictional claims in published maps and institutional affiliations. 


\section{Affiliations}

Danielle Lake ${ }^{1} \cdot$ Kathleen Flannery ${ }^{2} \cdot$ Morgan Kearns $^{3}$

Kathleen Flannery

kflannery@anselm.edu

Morgan Kearns

mkearns4@elon.edu

1 Elon University, 50 Campus Drive, Elon, NC 27244, USA

2 Psychology Department, Saint Anselm College, 100 Saint Anselm Drive, Manchester, NH 03102, USA

3 Elon University, Campus Box 14182, Elon, NC 27244, USA 